\title{
Identification of the Organizational Performance Indicators More Favorable to the Reality of a Bank: Use of the Data Envelopment Analysis (DEA) and Balance Scored Card (BSC)
}

\author{
Daniela Hereid L'* and Gustavo S. Queiroz ${ }^{2}$ \\ ${ }^{1}$ Optimization and Intelligence Management Laboratory - LOGIN, 1700 Av. Paranjana, Fortaleza, Ceara State, Brazil \\ ${ }^{2}$ University of the State of Ceara, 1700 Av. Paranjana, Fortaleza, Ceara State, Brazil
}

\begin{abstract}
This article aims highlight the importance of the quantitative methods application in conjunction with organizational tools aid in the decision-making process. The need to work with countless data is a constant in the business world. Often the manager loses time analyzing data that are not important at that moment which may result in inefficiency. In this paper are proposals a project development making use of mathematical programming as a precious tool in decision management, resulting in a reduction of time spent of analysis for business decisions and greater accuracy. To highlight the importance of a multidisciplinary approach to redefine problems outside of normal boundaries, a bank would be the organization to work within all their agencies treats as DMU of the system. From the modeling, it is possible to identify those agencies that will provide efficient benchmarking for inefficient agencies, pointing actions to be directed to become efficient. Takes place here, a complete sensitivity analysis on alternative scenarios that could be generated by a decision maker. The proposed project would be performed in three stages, considering the case of a private sector bank: exploratory and data treatment; semi-structured interviews with the managers; analyze the relative efficiencies among the DMUs with the chosen sets of Inputs and Outputs through Data Envelopment Analysis - DEA. An analysis of the results from the standpoint of Economic Efficiency and Organizational Efficiency (BSC) would be an object of discussion.
\end{abstract}

Keywords: DEA; Balance score card; Efficiency; Multidisciplinary approach

\section{Introduction}

In a competitive environment, it is a recurrent concern of the managers of various types of organizations and industries to monitor the performance of the organizations they manage.

If the company fails to adopt an adequate measurement and performance evaluation, it will find difficulties to communicate their expectations regarding the performance to subordinates. The manager also cannot know what really is going on within the organization and do not will be able to identify failures, thus cannot provide appropriate feedback and will not be possible to identify the performance to be rewarded Rummler (1994).

Kaplan [1] believes than performance evaluation indicators is an opportunity to discover new ways to collaborate with the organization reaching of their strategic objectives and not being just another task to be undertaken.

The performance indicators are used by organizations to raise their performance and may be financial or non-financial, or even coming from tangible or intangible assets. The first ones are more easily recognized and have better data extraction, while intangibles have a more complex control. Tangible assets are more easily measured and managed, especially when referring to financial indicators. The financial indicators although they have wide accessibility, mainly because of disclosure rules in force should be evaluated if they are really useful because they can be used not only for convenience and accessibility.

Jusoh [2] also conducted a study involving performance indicators and realized that nonfinancial measures are gaining ground, especially regarding measures for customers. Another conclusion is found by the authors that using financial measures only is not sufficient to satisfactorily measure the performance companies' management.
The performance index must be controllable by the manager. If the manager is not given autonomy to influence the measurement and control it, the measure loses its motivational power. Two other features should be involved in measures: they must be accurate; it comes down to accuracy and objectivity, and are understandable, considering that the manager must know what they are measuring.

The choice of the indicators and their use for demarcation of responsibility for them within the organization, also play a large effect on the culture of the organization. They work as an opportunity to discover new ways to help the organization to meet their strategic goals and not simply be just another task to be performed Kaplan [1]

This article aims at first highlight the importance of the application of quantitative methods (DEA) in conjunction with organizational tools (BSC) aid in the decision-making process. There is a brief explanation of these tools and technique below.

As in many organizations, banks employ various inputs to provide various services (outputs). Which ratio should be selected becomes an issue of evaluators when a great number of related financial indicators are involved. One of the solving methods is to aggregate average among all indicators in order to integrate a single measurement.

*Corresponding author: Daniela Hereid, Optimization and Intelligence Management Laboratory - LOGIN, 1700 Av. Paranjana, Fortaleza, Ceara State, Brazil, E-mail: danihereid@gmail.com

Received March 28, 2013; Accepted May 10, 2013; Published May 16, 2013

Citation: Daniela Hereid L, Queiroz GS (2013) Identification of the Organizational Performance Indicators More Favorable to the Reality of a Bank: Use of the Data Envelopment Analysis (DEA) and Balance Scored Card (BSC). J Entrepren Organiz Manag 2: 103. doi:10.4172/2169-026X.1000103

Copyright: (c) 2013 Daniela Hereid L, et al. This is an open-access article distributed under the terms of the Creative Commons Attribution License, which permits unrestricted use, distribution, and reproduction in any medium, provided the original author and source are credited. 
Citation: Daniela Hereid L, Queiroz GS (2013) Identification of the Organizational Performance Indicators More Favorable to the Reality of a Bank: Use of the Data Envelopment Analysis (DEA) and Balance Scored Card (BSC). J Entrepren Organiz Manag 2: 103. doi:10.4172/2169026X.1000103

Page 2 of 4

The article published by Farrel [3] entitled "The Measurement of Productive Efficiency" in the Journal of the Royal Statistical Society, presents new concepts for the analysis of activities, which defines a single measure of efficiency of a DMU taking into consideration multiple inputs and products. Farrel has proposed that the basic concepts of efficiency covers two aspects: Technical Efficiency, which reflects the ability of a DMU obtain maximum production from a set of inputs known and allocative efficiency, which reflects the ability of a DMU use the inputs in proportions optimized through minimizing the costs of this allocation. These two measures provide a combined measure called for economic Efficiency Total. However, the discussion of DEA models present here is brief, with relatively little technical details because this is not the main objective of this article. More detailed reviews of the methodology are presented by Charnes [4].

The scenario of globalization that has consolidated in recent years has triggered a series of new challenges for companies. Among these challenges, this further solidified was the constant search for mechanisms of performance evaluation not only on the financial aspects, but mainly the characterization of the performance of the companies to make them more competitive. It was there arose the BSC (Balanced Scorecard) with goals to create groups of measures of performance that integrates the financial perspective with the organizational perspective of the company (internal processes, customer satisfaction, learning, growth, etc).

\section{Theoretical Review and Hypothesis}

Data Envelopment Analysis (DEA) is a relatively new "data oriented" approach for evaluating the performance of a set of peer entities called Decision Making Units (DMUs) which convert multiple inputs into multiple outputs

In their originating study, Charnes (1978) described DEA as a 'mathematical programming model applied to observational data [that] provides a new way of obtaining empirical estimates of relations - such as the production functions and/or efficient production possibility surfaces - that are cornerstones of modern economics. Relative efficiency in DEA accords with the following definition, which has the advantage of avoiding the need for assigning a priori measures of relative importance to any input or output:

Efficiency - Extended Pareto-Koopmans Definition: Full (100\%) efficiency is attained by any DMU if and only if none of its inputs or outputs can be improved without worsening some of its other inputs or outputs.

Relative Efficiency: A DMU is to be rated as fully (100\%) efficient on the basis of available evidence if and only if the performances of other DMUs does not show that some of its inputs or outputs can be improved without worsening some of its other inputs or outputs.

With the identification of inefficient agencies, it will be possible to work on the right inputs to produce better outputs. An input as number of employees, for example, will indicate if there in the agency have too many people working or the need to hire more employees. The use of the DEA technique provides to identify and change multiply inputs in the same time to reach a greater efficiency of the agencies studied.

\section{Methodology}

In this paper we present proposals for the development of a project that condenses the theory presented in the introduction to the importance of making use of mathematical programming as a tool in decision management. The proposed project would be performed in stages, considering the case of a private sector bank, as follows:

1. Initially the data will be collected on the variables that make up the performance indicators used by the Bank. With these data, there will be an exploratory analysis of them to then, be performed a data treatment by multivariate techniques (cluster analysis, and factorial regression) to determine which indicators are crucial to the performance of the Bank.

2. In the next phase relationships between performance indicators and variables will be validated by the Bank's directors and superintendents through semi-structured interviews.

3. In this last phase will assess the relative efficiencies among the DMUs with their chosen sets of Inputs and Outputs through Data Envelopment Analysis - DEA.

The methodology aims to characterize efficient and inefficient agencies as well as to identify factors that can be worked in order to generate a better outcome for agencies as inefficient provided by mathematical programming model DEA. In this analysis, management will be highlighted financial organizations that serve as efficient benchmarking or references to organizations identified as inefficient.

The BCC_O DEA model was chosen in this analysis in order to maximize productivity (output) of each agency based on the input of each, as the formulation below:

$$
\begin{aligned}
& \operatorname{Max} \sum_{j=1}^{s} u_{j} Y_{j A}-u \\
& \text { Subject to } \\
& \sum_{i=1}^{m} v_{i} X_{i k}=1 \\
& \sum_{j=1}^{s} u_{j} Y_{j k}-\sum_{i=1}^{m} v_{i} X_{i k}-u \leq 0, \text { for } \mathrm{k}=1,2, \ldots . ., \mathrm{n} \\
& u_{j} e v_{i} \geq 0 \forall j, i
\end{aligned}
$$

Whose efficiency frontier can be seen in Figure 1.

\section{Sample plan of analysis}

To be made a test of this prototype, it is suggested to work initially with the factors obtained under two visions: organizational (BSC) and economic.

\section{Vision of economic efficiency}

Factors of Inputs:

- Number of Employees: The total number of people with formal jobs of each DMU.

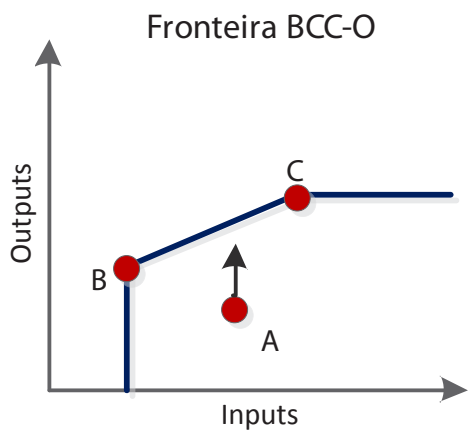

Figure 1: Output (BCC_O) oriented. 
Citation: Daniela Hereid L, Queiroz GS (2013) Identification of the Organizational Performance Indicators More Favorable to the Reality of a Bank: Use of the Data Envelopment Analysis (DEA) and Balance Scored Card (BSC). J Entrepren Organiz Manag 2: 103. doi:10.4172/2169026X.1000103

Page 3 of 4

- Leverage:

- Delinquency Rate: expresses bad loans granted by the Agency. The lower this rate best for Agency.

- Fixed Assets to Net Worth ratio: Nothing more than the proportion of the equity of the Agency applied in permanent asset. The lower this number, the better, is there will be more resources for the spins of the activity.

- Operating Cost: The smaller, it is better.

Factors of Outputs

- Income statement

- Return on equity

- Operating Profit

- Earnings

- Equity: In general, you can think of equity as ownership in any asset after all debts associated with that asset are paid off.

\section{Vision of organizational efficiency}

In this context, the title of examples, we show below some factors of inputs and outputs to analyze the relative effectiveness of various units of a bank in light of organizational perspective.

Factors of Inputs

- Strategy and Operations (SO): Represents the volume of financial transactions and credit. Includes the amount of capital credit, lines of investments, loans in foreign trade, international financial transfers, funding, fees on services, value of salaries paid.

- Internal processes (IP): represents the index of control processes of the unit. Involves: business rules of the company (standards, policies, guidelines, regulations, etc), countable processes and management of internal accounts.

- Organizational Behavior (OB): represents the learning and quality of work. Working time (not considering overtime). Quality of life in the company.

Factors of Outputs

- Economic result (ER): In financial terms, represents the result obtained by the unit.

- Customers (C): represents the satisfaction of customers, obtained through random sample not identified.

- Society (S): represents the participation of banking units in society as provoking social changes.

For a better understanding, we propose in this work a first view of the results of DEA methodology applied to the management of bank branches, from simulated data (Table 1 and 2).

\section{Conclusion}

Performance measurement and analysis is crucial for steering the organization to realize its strategic and operational goals. Relevant performance indicators and their relationships to goals and activities need to be determined and analyzed.

After running the model, only ten agencies have been considered efficient. In a more detailed study, you can use a benchmarking when analyzing which agencies are references for the inefficient and in which inputs/outputs. This way, the administrator does not need to deal with a large number of indicators and may focus on the weaknesses of their respective agencies.

\begin{tabular}{|c|c|c|c|c|c|c|}
\hline Agencies & (O) ER & (O) C & (O) $\mathrm{S}$ & (I) $\mathrm{SO}$ & (I) IP & (I) $\mathrm{OB}$ \\
\hline A1 & 295 & 420 & 50 & 333 & 564 & 500 \\
\hline A2 & 443 & 420 & 60 & 400 & 531 & 576 \\
\hline A3 & 476 & 420 & 30 & 468 & 466 & 500 \\
\hline $\mathrm{A} 4$ & 458 & 420 & 50 & 464 & 319 & 525 \\
\hline A5 & 535 & 420 & 40 & 405 & 459 & 600 \\
\hline A6 & 600 & 420 & 80 & 373 & 600 & 500 \\
\hline A7 & 506 & 420 & 70 & 402 & 418 & 585 \\
\hline A8 & 470 & 420 & 90 & 407 & 523 & 573 \\
\hline A9 & 478 & 420 & 130 & 415 & 584 & 413 \\
\hline A10 & 474 & 420 & 60 & 435 & 495 & 600 \\
\hline A11 & 354 & 420 & 50 & 397 & 516 & 600 \\
\hline A12 & 335 & 420 & 50 & 378 & 482 & 560 \\
\hline A13 & 335 & 420 & 50 & 378 & 520 & 600 \\
\hline A14 & 393 & 420 & 40 & 398 & 383 & 428 \\
\hline A15 & 524 & 420 & 60 & 494 & 541 & 549 \\
\hline A16 & 344 & 420 & 30 & 392 & 527 & 600 \\
\hline A17 & 402 & 420 & 50 & 384 & 559 & 579 \\
\hline A18 & 421 & 420 & 30 & 324 & 538 & 600 \\
\hline A19 & 394 & 420 & 40 & 413 & 443 & 501 \\
\hline A20 & 422 & 420 & 50 & 454 & 551 & 600 \\
\hline A21 & 455 & 420 & 50 & 442 & 533 & 582 \\
\hline A22 & 334 & 420 & 60 & 346 & 587 & 600 \\
\hline A23 & 479 & 420 & 40 & 545 & 558 & 557 \\
\hline A24 & 381 & 420 & 50 & 391 & 489 & 576 \\
\hline A25 & 570 & 420 & 50 & 474 & 417 & 600 \\
\hline A26 & 376 & 420 & 50 & 445 & 583 & 600 \\
\hline A27 & 492 & 420 & 40 & 399 & 550 & 558 \\
\hline A28 & 520 & 420 & 50 & 446 & 466 & 585 \\
\hline A29 & 480 & 420 & 40 & 448 & 527 & 600 \\
\hline A30 & 460 & 420 & 50 & 469 & 585 & 482 \\
\hline A31 & 570 & 420 & 40 & 384 & 522 & 600 \\
\hline A32 & 443 & 420 & 70 & 470 & 566 & 600 \\
\hline A33 & 508 & 420 & 70 & 403 & 419 & 600 \\
\hline A34 & 396 & 420 & 60 & 370 & 591 & 600 \\
\hline A35 & 509 & 420 & 60 & 573 & 571 & 600 \\
\hline A36 & 460 & 420 & 60 & 484 & 522 & 600 \\
\hline A37 & 486 & 420 & 50 & 454 & 411 & 600 \\
\hline A38 & 578 & 420 & 50 & 495 & 590 & 600 \\
\hline A39 & 338 & 420 & 60 & 458 & 578 & 600 \\
\hline A40 & 471 & 420 & 70 & 452 & 485 & 500 \\
\hline A41 & 377 & 420 & 40 & 428 & 581 & 543 \\
\hline A42 & 380 & 420 & 40 & 498 & 590 & 600 \\
\hline A43 & 374 & 420 & 40 & 417 & 575 & 600 \\
\hline A44 & 342 & 400 & 50 & 427 & 432 & 600 \\
\hline A45 & 530 & 400 & 40 & 496 & 560 & 600 \\
\hline A46 & 374 & 420 & 40 & 407 & 511 & 600 \\
\hline A47 & 439 & 400 & 50 & 415 & 574 & 600 \\
\hline A48 & 424 & 400 & 80 & 444 & 466 & 600 \\
\hline A49 & 360 & 400 & 50 & 423 & 580 & 600 \\
\hline A50 & 398 & 400 & 50 & 406 & 558 & 600 \\
\hline
\end{tabular}

Table 1: Simulated Data (input/output of the Vision of Organizational Efficiency). 
Citation: Daniela Hereid L, Queiroz GS (2013) Identification of the Organizational Performance Indicators More Favorable to the Reality of a Bank: Use of the Data Envelopment Analysis (DEA) and Balance Scored Card (BSC). J Entrepren Organiz Manag 2: 103. doi:10.4172/2169026X.1000103

Page 4 of 4

\begin{tabular}{|c|c|c|}
\hline Rank & DMU & Score \\
\hline 1 & A33 & $100,00 \%$ \\
\hline 2 & $\mathrm{~A} 1$ & $100,00 \%$ \\
\hline 3 & A31 & $100,00 \%$ \\
\hline 4 & A25 & $100,00 \%$ \\
\hline 5 & A4 & $100,00 \%$ \\
\hline 6 & A18 & $100,00 \%$ \\
\hline 7 & A6 & $100,00 \%$ \\
\hline 8 & A7 & $100,00 \%$ \\
\hline 9 & A14 & $100,00 \%$ \\
\hline 10 & A9 & $100,00 \%$ \\
\hline 11 & A22 & $99,39 \%$ \\
\hline 12 & A5 & $99,25 \%$ \\
\hline 13 & $\mathrm{~A} 12$ & $97,37 \%$ \\
\hline 14 & A8 & $97,17 \%$ \\
\hline 15 & A13 & $94,75 \%$ \\
\hline 16 & A24 & $94,73 \%$ \\
\hline 17 & A3 & $94,64 \%$ \\
\hline 18 & A34 & $94,20 \%$ \\
\hline 19 & A28 & $93,49 \%$ \\
\hline 20 & A40 & $93,23 \%$ \\
\hline 21 & A19 & $93,22 \%$ \\
\hline 22 & A37 & $93,21 \%$ \\
\hline 23 & $\mathrm{~A} 2$ & $92,81 \%$ \\
\hline 24 & $\mathrm{~A} 27$ & $92,69 \%$ \\
\hline 25 & A11 & $92,08 \%$ \\
\hline 26 & A17 & $92,03 \%$ \\
\hline 27 & A48 & $90,85 \%$ \\
\hline 28 & A16 & $90,25 \%$ \\
\hline 29 & A15 & $89,80 \%$ \\
\hline 30 & A46 & $89,71 \%$ \\
\hline 31 & A10 & $89,50 \%$ \\
\hline 32 & A44 & $88,69 \%$ \\
\hline 33 & A38 & $88,42 \%$ \\
\hline 34 & A30 & $88,37 \%$ \\
\hline 35 & A29 & $86,41 \%$ \\
\hline 36 & A21 & $85,96 \%$ \\
\hline 37 & A41 & $85,91 \%$ \\
\hline 38 & A43 & $84,94 \%$ \\
\hline 39 & A50 & $84,88 \%$ \\
\hline 40 & A47 & $83,67 \%$ \\
\hline 41 & A45 & $83,42 \%$ \\
\hline 42 & A23 & $83,14 \%$ \\
\hline 43 & A32 & $83,07 \%$ \\
\hline 44 & $\mathrm{~A} 20$ & $83,02 \%$ \\
\hline 45 & A39 & $82,38 \%$ \\
\hline 46 & A26 & $82,36 \%$ \\
\hline 47 & A36 & $82,17 \%$ \\
\hline 48 & A35 & $81,66 \%$ \\
\hline 49 & A49 & $81,41 \%$ \\
\hline 50 & A42 & $75,84 \%$ \\
\hline
\end{tabular}

This article emphasizes the importance to seek a multidisciplinary approach to redefine problems outside of normal boundaries and reach solutions based on a new understanding of complex situations. Combine the theoretical knowledge about organizational management with science mathematics and implementation in computer programs that facilitate the task of the manager is necessary in a competitive environment.

\section{References}

1. Kaplan RS, Norton DP (1997) Estratégia em ação - Balanced Scorecard (13 edn.), Rio de Janeiro, Brazil.

2. Jusoh R, Ibrahim DN, Zainuddin $Y$ (2008) The performance consequence of multiple performance measures usage. Int J Prod Perform Manag 57: 119-136.

3. Farrel MJ (1957) The Measurement of the Productive Efficiency. J R Stat Soc 120: 253-290.

4. Charnes A, Cooper WW, Lewin AY, Seiford LM (1995) Data Envelopment Analysis: Theory, Methodology and Applications, Springer Publishers.

Model Name $=$ DEA-Solver Pro5.0/ CCR $($ CCR-O $)$

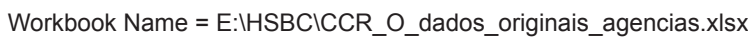

Table 2: Efficiency rank of 50 agencies. 